\title{
Surgical aortic valve replacement in the transcatheter era: It is all about teamwork
}

\author{
Oz M. Shapira, MD
}

\author{
From the Department of Cardiothoracic Surgery, Hadassah Hebrew University Medical Center, Jerusalem, Israel. \\ Disclosures: Author has nothing to disclose with regard to commercial support. \\ Received for publication Sept 6, 2015; accepted for publication Sept 8, 2015; available ahead of print Oct 10, \\ 2015. \\ Address for reprints: Oz M. Shapira, MD, Department of Cardiothoracic Surgery, Hadassah Hebrew University \\ Medical Center, POB 12000, Ein Kerem, Jerusalem 91120, Israel (E-mail: ozshapira@ hadassah.org.il). \\ J Thorac Cardiovasc Surg 2015;150:1589-90 \\ 0022-5223/ $\$ 36.00$ \\ Copyright (C) 2015 by The American Association for Thoracic Surgery \\ http://dx.doi.org/10.1016/j.jtcvs.2015.09.045
}

\section{Alone we can do so little; together we can do so much!}

\section{-Helen Keller}

Surgical aortic valve replacement (sAVR) was introduced in the early 1960s, resulting in a dramatic improvement in survival and quality of life of patients with severe valvular aortic stenosis. Although sAVR outcomes markedly improved through the years, as many as a third of patients with aortic stenosis were treated conservatively, either because they were reluctant to have major surgery at a late stage in their lives or because they were not deemed operative candidates by the primary care physician, cardiologist, and cardiac surgeon. ${ }^{1}$ Transcatheter aortic valve implantation (TAVI) was first introduced a decade ago, aiming initially to expand the interventional options for this high-risk elderly group of patients. Multiple reports confirmed that TAVI has become a safe and effective treatment modality. ${ }^{2,3}$ The immediate result was a rapid, enthusiastic, and at times inappropriate use of TAVI in either extremely high-risk or low- and medium-risk categories.

In this issue of the Journal, Martin and colleagues ${ }^{4}$ assessed the impact of TAVI, introduced to their institution in 2007, on the volume and outcomes of sAVR through a decade between 2003 and 2013. ${ }^{4}$ The institution of Martin and colleagues ${ }^{4}$ is the sole regional provider of cardiac surgery and advanced percutaneous cardiovascular interventions in Quebec, Canada. The important findings in this large, single-institutional observational study consist of the following: (1) the volume of sAVR consistently increased, from 90 to 100 to 170 to 180 cases/y, despite a parallel increase in the TAVI case volume from 2007 onward; (2) the clinical outcomes of sAVR markedly improved, despite an overall similar baseline risk profile.

Martin and colleagues ${ }^{4}$ interpreted these two key observations as surprising and perhaps counterintuitive. Both phenomena are, however, actually to be expected and are related to an exceedingly important feature of the program-teamwork. A fundamental component of the

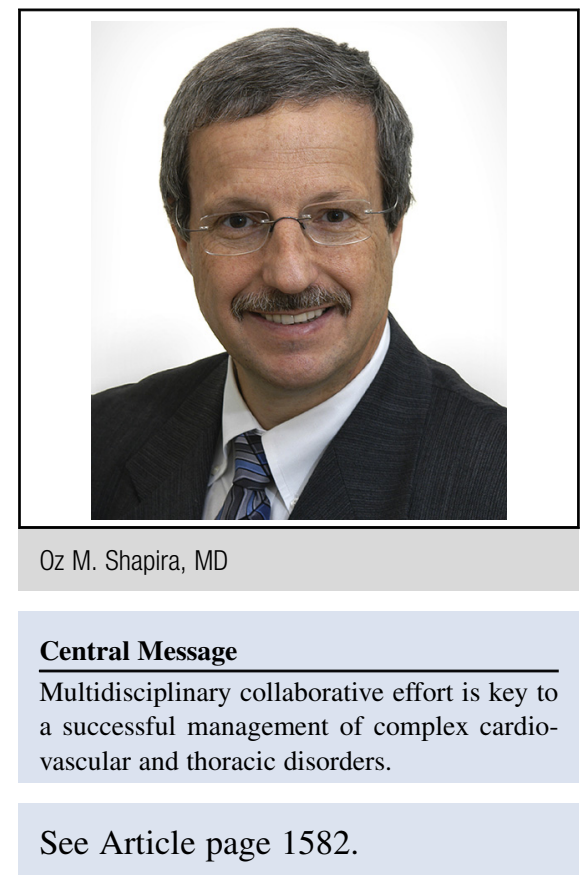

institution's TAVI program was strict implementation of the Heart Team concept. The favorable impact of a multidisciplinary approach to a complex clinical problem has been previously demonstrated in such areas as surgical oncology and transplantation but has been a focus of attention in cardiovascular diseases only recently. ${ }^{5}$ The Heart Team concept in a TAVI program is currently defined as a class I indication by the prominent cardiovascular professional societies best practice clinical guidelines. ${ }^{6}$ It is also 1 of the 6 prerequisites for TAVI program approval mandated by the Centers for Medicare and Medicaid Services in the United States. ${ }^{7}$ Although not specifically measured by Martin and colleagues, ${ }^{4}$ the implementation of the Heart Team concept undoubtedly increased the patient referrals and had an enormous impact on patient selection. Regional primary care physicians and cardiologists were more likely to refer patients with aortic stenosis to a multidisciplinary team that would carefully evaluate each patient in an objective, balanced, and unbiased fashion. A group of cardiovascular subspecialists, rather than a single practitioner, is more likely to interpret and integrate the clinical and imaging data better and recommend an appropriate patient-specific treatment plan that is in line with the most recent published data and best clinical practice guidelines. In this institution, during the post-TAVI period, $28 \%$ 
percent of patients who were initially referred for possible TAVI had sAVR $(17 \%)$ or were treated medically $(11 \%)$.

The improvement in clinical outcomes of sAVR during the study period was due in part to the more refined patient selection process, but undoubtedly was also due to collaborative efforts of other components of the cardiovascular team, including anesthesiologists, intensive care specialists, and the often "transparent" but equally important members-perfusionists, nurses, and many other caregivers. For example, a $21 \%$ reduction in allogeneic blood transfusion can only be achieved by developing a comprehensive blood conservation strategy embraced by the entire team. Continued improvement of outcomes of sAVR observed in the study of Martin and colleagues ${ }^{4}$ is in line with other reports. ${ }^{8}$

Teamwork had a favorable impact not only on sAVR but also on the TAVI outcomes. The article summarizes the TAVI results in its early phase of the institutional learning curve. Despite this, the incidence of major complications was impressively similar to that reported by large registries reporting on thousands of patients treated through a much longer period. ${ }^{2,3,8}$ Similar to other reports, the current article highlights the 4 major drawbacks of TAVI relative to sAVR: residual aortic insufficiency, need for permanent pacemaker implantation, vascular complications, and uncertain long-term prosthetic valve durability. ${ }^{2,3,8}$ Together these data underscore the fact that both sAVR and TAVI outcomes improve with time. Future comparisons of TAVI outcomes against the criterion standard of time-tested and proven SAVR should take these dynamic changes into consideration.

The final component that played a major role in the improvement of sAVR outcomes is the mere fact that data were prospectively collected and entered into a cardiovascular database. Establishing a cardiovascular clinical database is the key and fundamental tool allowing in-depth assessment of the 3 components of quality of care: structure, process, and outcomes. ${ }^{9}$ Linking to the Society of Thoracic Surgeons National Database afforded Martin and colleagues ${ }^{4}$ with the opportunity to use a set of well-recognized variable definitions and risk-assessment algorithms to calculate predicted mortality as well as observed versus expected mortality ratios. These parameters are useful (albeit not perfect) tools for patient selection and quality assessment. Having a clinical database with a 5\% error rate of missing or inaccurate data reflects not only a strong institutional commitment but also a major team effort, including surgeons, database managers, and auditors. Considering a database as an integral component of a cardiovascular center seems trivial nowadays in North America and selected countries around the world. This is not the situation in way too many cardiac surgery programs, however, as a result of lack of national or professional society level regulation, cultural issues, and a lack of institutional and departmental commitment and incentive to invest the required resources. ${ }^{10}$

In summary, Martin and colleagues ${ }^{4}$ should be congratulated for the significant improvement of outcomes after sAVR. They were able to achieve these remarkable results in large part as a result of switching from the old paradigm of practicing in "silos" to teamwork that is based on a multidisciplinary collaborative effort. The concept of multidisciplinary team approach should become the standard of care for a wide spectrum of cardiovascular and thoracic disorders.

\section{References}

1. Bach DS, Siao D, Girard SE, Duvernoy C, McCallister BD Jr, Gualano SK. Evaluation of patients with severe symptomatic aortic stenosis who do not undergo aortic valve replacement: the potential role of subjectively overestimated operative risk. Circ Cardiovasc Qual Outcomes. 2009;2:533-9.

2. Walther T, Hamm CW, Schuler G, Berkowitsch A, Kötting J, Mangner N, et al; GARY Executive Board. Perioperative results and complications in 15,964 transcatheter aortic valve replacements: prospective data from the GARY Registry. $J$ Am Coll Cardiol. 2015;65:2173-80.

3. Tamburino C, Barbanti M, D'Errigo P, Ranucci M, Onorati F, Covello RD, et al. OBSERVANT Research Group. 1-Year outcomes after transfemoral transcatheter or surgical aortic valve replacement: results from the Italian OBSERVANT Study. J Am Coll Cardiol. 2015;66:804-12.

4. Martin E, Dagenais F, Voisine P, Dumont E, Charbonneau E, Baillot R, et al. Surgical aortic valve replacement outcomes in the transcatheter era. J Thorac Cardiovasc Surg. 2015;150:1582-8.

5. Holmes DR, Rich JB, Zoghbi WA, Mack MJ. The heart team of cardiovascular care. J Am Coll Cardiol. 2013;61:903-7.

6. Nishimura RA, Otto CM, Bonow RO, Carabello BA, Erwin JP III, Guyton RA, et al. American College of Cardiology; American College of Cardiology/American Heart Association; American Heart Association. 2014 AHA/ACC guideline for the management of patients with valvular heart disease: a report of the American College of Cardiology/American Heart Association Task Force on Practice Guidelines. J Thorac Cardiovasc Surg. 2014;148:e1-132. Erratum in: J Thorac Cardiovasc Surg. 2014;64:1763.

7. Jacques L, Jensen TS, Schafer J, Fulton S, Schott L, Baldwin J. Decision memo for transcatheter aortic valve replacement (TAVR) (CAG-00430N). Baltimore, MD: Centers for Medicare \& Medicaid Services; 2012. Available at: https:// www.cms.gov/medicare-coverage-database/details/nca-decision-memo.aspx? NCAId $=257 \&$ NcaName $=$ Transcatheter + Aortic + Valve + Replacement $+($ TAVR $)$ $\& b c=$ AiAAAAAAIAAA\&. Accessed September 9, 2015.

8. Mohr FW, Holzhey D, Möllmann H, Beckmann A, Veit C, Figulla HR, et al; GARY Executive Board. The German Aortic Valve Registry: 1-year results from 13,680 patients with aortic valve disease. Eur J Cardiothorac Surg. 2014;46:808-16.

9. Shapira OM. Quality assessment in cardiac surgery: measuring fairly and easily, focusing on what can be changed. J Thorac Cardiovasc Surg. 2014;148:3082-3.

10. Shapira OM, Badhwar V, Shahian D, Jacobs JP, Izhar U, Bao Y, et al. International participation in the Society of Thoracic Surgeons National Database. Ann Thorac Surg. 2014;97:1127-30. 